\title{
The new new general practice: the changing philosophies of primary care
}

\author{
Anna Livingstone, David Widgery
}

Gill Street Health Centre, London E14 8HQ

Anna Livingstone, MRCGP, general practitioner

David Widgery, MB, general practitioner

BrMed f 1990;301:708-10

The forerunner of the surgery dispensary

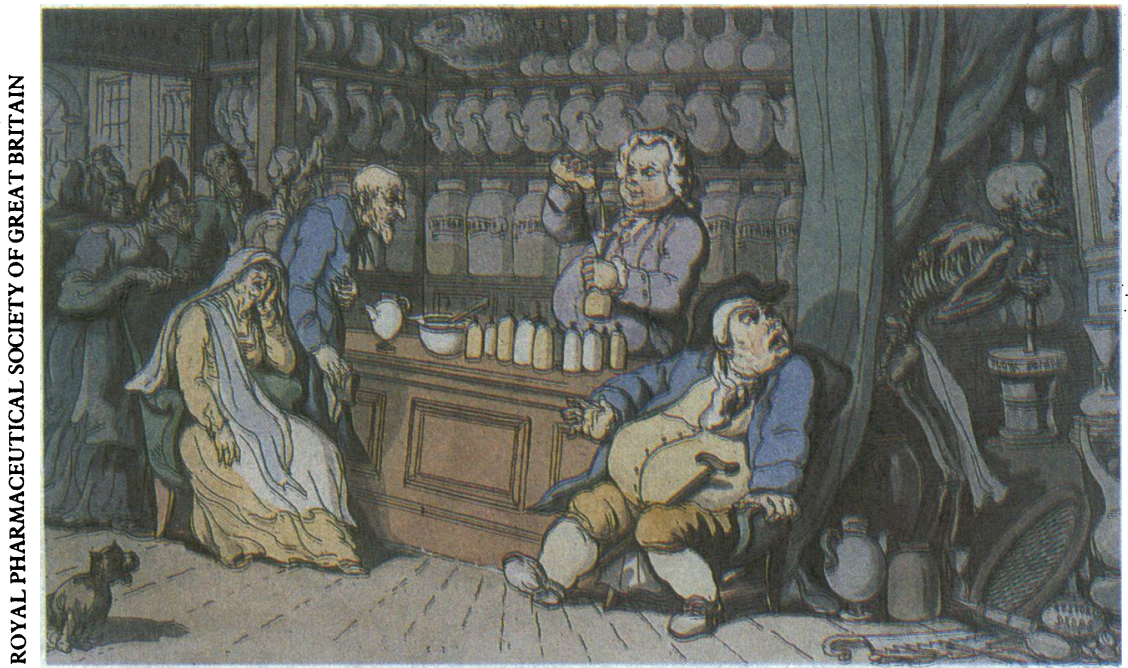

The original general practitioner was, let us be frank, a gentleman dependent on fees, generally of low status and ambition, who touted for clinical custom in direct competition with his fellows. The origin of our profession was in individualism and entrepreneurship, in doctors who were not so much clinicians as supporters, explainers or mystifiers, and conductors of rituals according to the expressed needs of the customer. Effective remedies were few, medical science irrelevant, and charlatanism inevitable. Infectious illnesses dominated nineteenth century medicine: such illness was either self limiting, in which case doctors' actions were immaterial, or fatal, when general practitioners had a largely ceremonial role. In patients with chronic or psychological illness he might offer support and venture prognosis. Until the end of the nineteenth century there was no thought of a national general practitioner service or universally available health care. If you could not afford the general practitioner it was the quacks, the friendly societies, or the workhouse.

\section{The panel scheme}

The reformers of the early twentieth century, notably Lloyd George, provided the first elements of social finance with which to deliver primary care. The Boer and first world wars had convinced the state of the need for a healthier workforce. "I hope our competition with Germany will not be in armaments alone," ruminated Lloyd George as he eyed the insurance scheme introduced by his European arch rivals. And the rise of an insurrectionary Labour movement across Europe after the war made reforms of the medical services an important political issue. The National Insurance Act 1911 had established a compulsory contribution towards health, which provided only the wage earner with the right of free consultations with general practitioners and medicine and sickness benefit if they were too ill to work, leaving the families and the unemployed unprovided for

This new service for the working class was, in fact, largely paid for by that class, was administered by the insurance companies (under new names), and produced a sharp increase in income for most of the doctors who worked with the panel scheme. They could now supplement their private fee paying work

$$
\text { how }
$$

\author{
how
} tion was still very poor and unsystematic. Vaccines, which had been available for decades, were utilised haphazardly. Care remained reactive, and the single handed principal and exploited assistant described by A J Cronin in The Citadel remained common. ${ }^{4}$ Thespian as well as clinical skill counted: the "good" general practitioner was still the one who responded appropriately to the patient's presentation of illness, so mutual self delusion clouded the consultation. But the responsibility of the general practitioner for the list was established, and with it the potential for planned health care in practice.

The science of general practice was what Tudor Hart dubbed "the Oslerian science"s of diagnosis in individual patients plus some therapeutics: the general practitioner was still a watered down hospital doctor who had either fallen off or never mounted the hospital career ladder through failure, poverty, or need for 


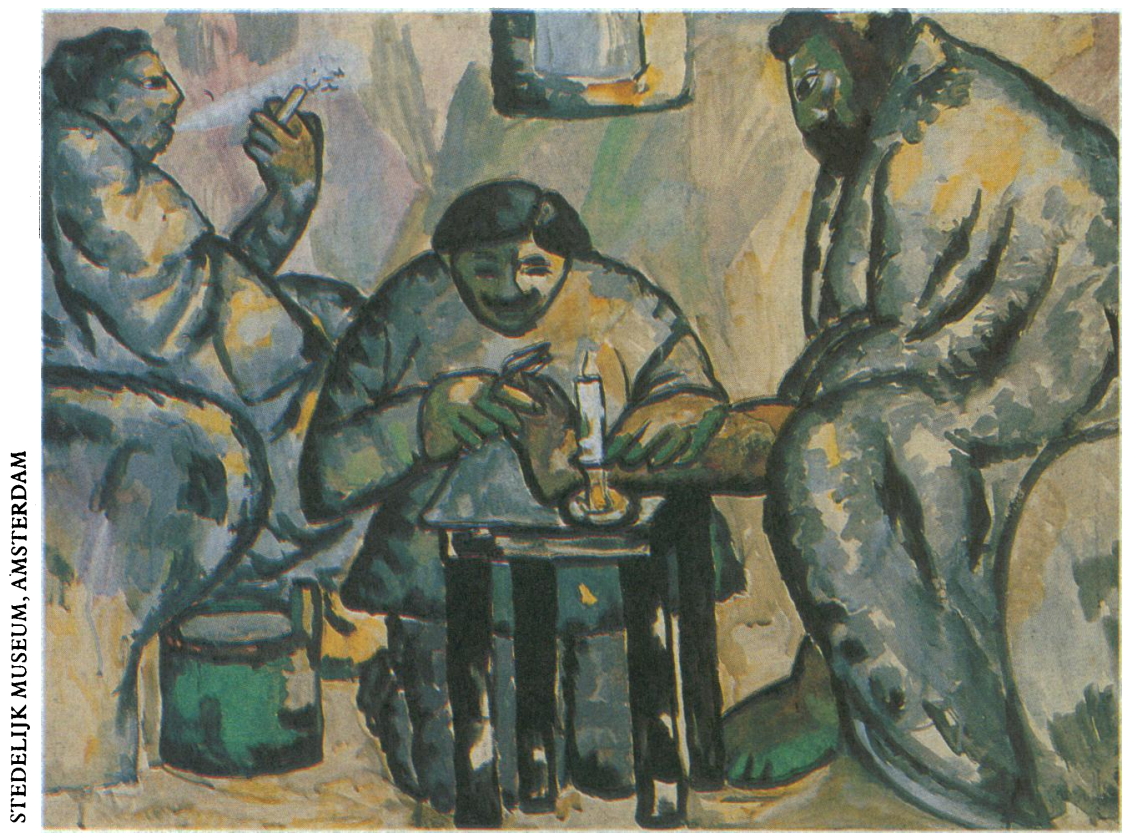

"Chiropodist in the Bathroom" by

Kazimir Malevich (1908-9)

immediate income. Premises were a lockup shop or the doctor's own home; there was seldom an appointment system, hardly any staff, and little development of records. Relations with teaching hospitals were poor (although in rural and non-teaching hospitals practitioners sometimes served as specialists). But practitioners themselves wanted more resources, better training, and more self respect. In this aspect, at least, the foundation in 1952 of the College of General Practitioners was an act of courage and imagination.

\section{Growing self confidence}

So while the NHS greatly enhanced and enriched hospital medicine, in general practice, despite the greatly extended patient access, prewar patterns of care persisted. Outside the affluent areas general practitioners had such a high workload and such rudimentary facilities that they were bound to be overwhelmed by the tide of bad medicine. The dominant picture was still the queue outside the sickshop.

In retrospect, the true importance of the 1966 charter, the outcome of an agitation initiated by the Medical Practitioners Union and taken up by the BMA, was to begin serious capital investment in primary care, although the character of that investment was anomalous in that primary care was a public service that was privately administered and very variable in its distribution. The Cost Rent scheme's favourable terms allowed the financing of specialised and innovative buildings, and staff reimbursement encouraged the employment of a reception team. Group practice was rewarded and became the norm. The Balint School, despite their clear explanatory limitations, identified a whole dimension of clinical dynamics in which the general practitioner was genuinely a specialist. Group dynamics as applied to families and child health deepened understanding of the work of "the family doctor." Postgraduate training mushroomed, the Royal College of General Practitioners and the university departments consolidated, and, intellectually, there was growing self confidence: in the decade between the famous 1968 BMF articles entitled "The New General Practice" and, say, the 1979 Oxford General Practitioner Trainee Group's A Guide to General Practice,' the published work on British general practice not only rapidly expanded but also yielded several classics. After William Pickles's pioneering work Keith Thompson, John Fry, and
Julian Tudor Hart showed just how much could be accomplished if you tried.

So by the end of the 1970s much more and much better quality work could be carried out in general practice. Increasing direct access to sophisticated investigations began to move internal medicine out of the hospital again: no longer did every difficult case need to be referred. A wider range of professional staff, most importantly health visitors, were "attached," although the word indicates their status. But the special potential of the British primary care system for early diagnosis and prevention was little explored: general practitioners were still too busy dealing with illness to worry about health (something which happened when the patient did not visit the surgery). Computers were sighted, but their remarkable ability as a clinical tool in surveillance of the practice list was not appreciated. And information systems were still rudimentary; "good" practices still poked all data into little envelopes that dated from 1911. Above all it was assumed to be a doctor led service and a doctor dominated team.

\section{The new new general practice}

Two new factors shaped the 1980s: compulsory vocational training and the end of growth in the hospital sector. Not only were many practices of vocationally trained doctors established (and began to train postgraduates themselves) but the hospitals had to hand back the patients whether they liked it or not. Peak flow meters, electrocardiographs, cervical speculums, well woman clinics, and blood pressure screening were increasingly the norm in general practice rather than the badge of a fanatic. What has been called the "new new general practice" sought to shift the paradigm again in order to make more sense out of the chaos of general practice. Under the theoretical impetus of Tudor Hart (whose 1988 A New Kind of Doctor remains its best credo) the new new general practices sought to use the microcomputer to unlock and utilise clinically the prevention potential locked up in conventional reactive general practice consultation: to move medical effort away from end organ salvage towards early diagnosis of risk; to shift from management of crises and response to illness that was led by demand toward proactive and anticipatory care and from management of disease in an individual patient to management of risk factors for populations and their members. This takes the bias towards prevention that is present in so much routine general practice on to a more systematic screening that is not always executed by doctors or initiated by patients but is based on the practice register. It applies above all to cardiovascular risk factors but also logically to any condition in which our present knowledge permits useful treatment before symptoms develop, including breast cancer, diabetes, depression, and cervical dysplasia.

The new approach seeks to augment the Oslerian approach with wider sociological and psychological insight from the past 20 years and to develop the potential for community participation in health. In our new Victorian age it needs to be highly sensitive to social class, racism, and deprivation and to use the growing body of work that links poverty and unemployment to ill health.

Such a shift in philosophy from the individualised view of the patient-doctor relationship may seem Utopian, something that a working general practitioner can never afford to be. But it begins to be possible as various other developments in the primary care team become widespread. When critical momentum is achieved this can happen fast, as the expansion of the anticipatory care teams movement 


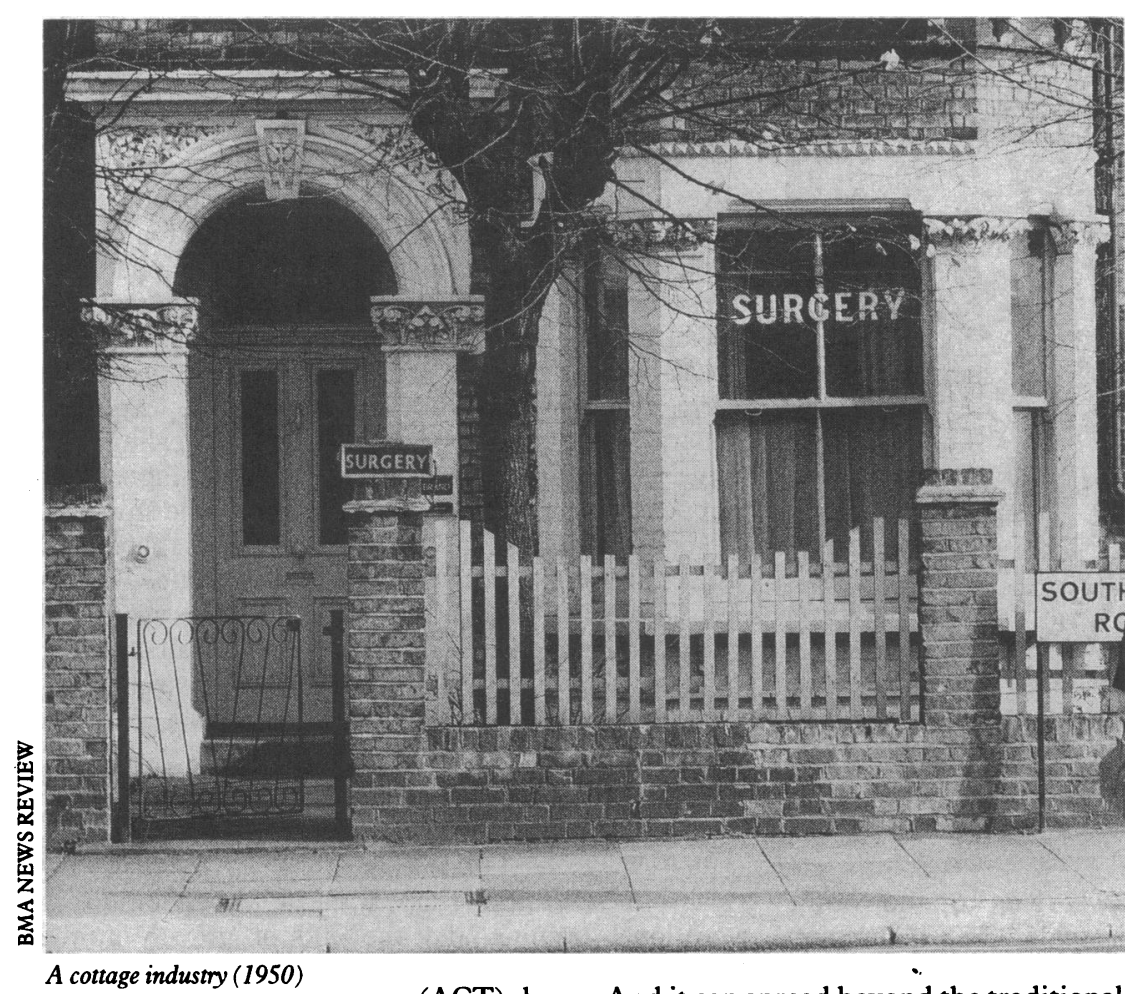

(ACT) shows. And it can spread beyond the traditional topics of good general practice. Doctors in inner city practices, who are endeavouring to reverse the inverse care law, are increasingly becoming innovators. The recently formed Association of General Practitioners in Urban Deprived Areas may prove to be a ginger group for medical reform in the same sort of way that the Association of Poor Law Doctors did in the nineteenth century and for the same reasons: it represents the self organisation of the doctors in personal contact with acute social and medical need.

\section{Ideals and restrictions}

Further progress depends on transforming the "attachment" model into a more democratic primary health care team in which the doctor is not always the key worker. And this entails general practitioners employing themselves or working alongside staff employed by the health authority who have a far wider range of skills than they do, including counsellors, psychologists; community physicians, health promotion nurses, practice managers, and community midwives - there are many things that practitioners do not do best themselves. It also requires moving audit in the narrow accounting sense into practical epidemiology, whereby we use self generated data as a clinical tool. And it probably requires a greater degree of zoning of primary care so that a particular primary health care team becomes responsible for a designated patch whose characteristics they come to know in detail. With such strong, well staffed platforms of primary care it would be possible to redraw rationally the division of labour between primary care and hospital and to begin to plan-clinically for individual care and organisationally in terms of the delivery of services to defined populations. Then audit and accountability to users could have real meaning.

Regrettably, but predictably, a decade of rich innovation in British primary care has ended in the government intervening to restrict expenditure and cost limit, to reverse the trend to lower list sizes and reassert the old language of consumers and rival professionals. But a new sort of general practitioner will not emerge out of consumerism, "entrepreneurship," and doctor hopping, just an old one in modern guise. Instead we need the planned convergence of general practice and community care and for this to be well resourced; closely integrated; and capable of innovation, self assessment, and accountability.

1 Bennett A. Elsie and the child. London: Cassell, 1924.

2 Roberts R. The classic slum. Harmonsworth: Penguin, 1973.

3 Brotherton cited in Widgery D. Health in danger. London: Macmillan, 1979:4.

4 Cronin AJ. The Citadel. London: Gollancz, 1937.

5 Hart JT. A new kind of doctor. London: Merlin, 1988.

6 The new general practice. London: BMA, 1968.

7 Oxford General Practitioner Trainee Group. A guide to general practice. Oxford: Blackwell, 1979. 